\title{
Global longitudinal strain is a hallmark of cardiac damage in mitral regurgitation: the Italian arm of the European Registry of mitral regurgitation (EuMiClip)
}

Ciro Santoro', Maurizio Galderisi ${ }^{1 *}$ (D, Roberta Esposito ${ }^{1}$, Agostino Buonauro', Juan Manuel Monteagudo², Regina Sorrentino ${ }^{1}$, Maria Lembo ${ }^{1}$, Covadonga Fernandez-Golfin ${ }^{2}$, Bruno Trimarco ${ }^{1}$ and Josè Luis Zamorano ${ }^{2}$

\begin{abstract}
Background: The search for reliable cardiac functional parameters is crucial in patients with mitral regurgitation (MR). In the Italian arm of the European Registry of MR, we compared the ability of global longitudinal strain (GLS) and left ventricular (LV) ejection fraction (LVEF) to detect cardiac damage in MR.

Methods: Five hundred four consecutive patients with MR underwent a complete echo-Doppler exam. A total of 431, 53 and 20 patients had degenerative, secondary and mixed MR, respectively. The main echocardiographic parameters, including LV and left atrial (LA) size measurements, pulmonary artery systolic pressure (PASP) and GLS were compared between patients with mild MR $(n=392)$ vs. moderate to severe MR $(n=112)$.

Results: LVEF and GLS were related one another in the pooled population, and separately in patients with mild and moderate/severe MR (all $p<0.0001$ ). However, a certain number of patients were above the upper or below the lower limits of the $95 \%$ confidence interval $(\mathrm{Cl})$ of the normal relation in the pooled population and in patients with mild MR. Only 2 patients were below the $95 \% \mathrm{Cl}$ in moderate to severe MR. After adjusting for confounders by separate multivariate models, LVEF and GLS were independently associated with LV and left atrial size in the pooled population and in mild and moderate/severe MR. GLS, but not LVEF, was also independently associated with PASP in patients with mild and moderate to severe MR.
\end{abstract}

Conclusions: Both LVEF and GLS are independently associated with LV and LA size, but only GLS is related to pulmonary arterial pressure. GLS is a powerful hallmark of cardiac damage in MR.

Keywords: Mitral regurgitation, Ejection fraction, Global longitudinal strain, Left atrial volume, Pulmonary hypertension

\section{Introduction}

The management of mitral regurgitation (MR), the most common valvular heart disease in the developed world [1], is mainly based on symptoms and signs of left ventricular (LV) dysfunction [2, 3]. Nevetherless, physicians face difficulties in detecting subtle progression of symptoms related to MR deterioration. Patients might unwittingly limit

\footnotetext{
* Correspondence: mgalderi@unina.it

1Department of Advanced Biomedical Science, Interdepartmental Laboratory of Cardiac Imaging, Federico II University Hospital, V. S. Pansini 5, bld 1, 80131 Naples, Italy

Full list of author information is available at the end of the article
}

their physical activity because of worsening exercise capacity and overt symptoms. In this clinical setting, physicians are requested to perform a strict follow-up mainly using echocardiographic parameters to detect early signs of LV failure. Nowadays, standard echocardiographic parameters, mainly two-dimensional derived $\mathrm{LV}$ ejection fraction (LVEF), are the most commonly used for evaluating LV function and prognosis in patients with MR [4]. However, despite a preserved LVEF, patients with chronic MR often hide an underlying myocardial contractility impairment [5]. LVEF does not take into account the amount of blood flow pushed back in the low-pressure left

(c) The Author(s). 2019 Open Access This article is distributed under the terms of the Creative Commons Attribution 4.0 International License (http://creativecommons.org/licenses/by/4.0/), which permits unrestricted use, distribution, and 
atrial (LA) cavity, which does not contribute to the effective stroke volume. Accordingly, patients with chronic MR and impaired LVEF may already have developed an irreversible, undiagnosed myocardial damage. The efforts of cardiologists should be addressed to search for alternative parameters that could unmask subtle, insidious changes in LV contraction.

LV deformation as assessed by speckle tracking echocardiography (STE) has proven to detect subclinical cardiac involvement and have prognostic value in different pathologic conditions [6, 7]. Analysis of myocardial LV deformation by STE also identified early LV dysfunction in patients with asymptomatic severe MR. GLS have demonstrated to predict 5-years all-cause mortality risk in patients with acute heart failure independently from LVEF values [8]. LV global longitudinal strain (GLS) at rest is also a strong predictor of long-term prognosis in a large population of asymptomatic patients with severe primary MR and preserved LVEF [9].

The purpose of the present study was to analyse differences between GLS and LVEF in detecting myocardial damage in patients with different etiology and mechanism of MR, enrolled in the Italian arm of the European Registry of MR (EuMiClip) [10]. Secondarily, we aimed to explore potential relationships between longitudinal deformation alteration and echocardiographic structural and functional parameters in patients with MR of different degree.

\section{Methods}

\section{Study population}

Over a 3-month period (March-June 2016), all consecutive patients with MR were prospectively recruited from the Italian arm of the European Registry of MR (EuMiClip). The registry protocol as well as the enrolment criteria have already been described [10]. Briefly, we included patients with different degree of MR and different etiology, among those referred to our echo-lab (Interdepartmental Laboratory of Cardiac Imaging, Federico II University Hospital, Naples, Italy). All patients gave their informed consent. Physical examination was performed and clinical history was collected. Complete baseline transthoracic echocardiographic studies, including STE acquired in three apical views, were computed. Blood pressure (BP) was measured at the end of the echocardiographic examination. Patients with trivial $M R$ and those with suboptimal image quality that precluded standard echocardiographic examination and/or longitudinal strain determination were excluded.

\section{Echocardiographic exam}

All echocardiographic examinations were performed according to the general procedures of EuMiClip Registry [10] and EACVI standardization of the echo report [11] on a Vivid E9 ultrasound machine (GE Healthcare, Horten, Norway), using a $2.5 \mathrm{MHz}$ transducer with harmonic capability. All the echo parameters were obtained as the average of three consecutive cardiac cycles in patients with sinus rhythm and of five consecutive cardiac cycles in presence of atrial fibrillation. LV dimensions were calculated according to the 2015 ASE/EACVI recommendations for chamber quantification [12], and LVEF was derived by measuring LV end-diastolic and end-systolic volumes with the biplane method. LA volume was indexed for body surface area (LAVi) [12]. Pulmonary artery systolic pressure (PASP) was derived from the tricuspid regurgitation velocity gradient and inferior vena cava size and reactivity as recommended by the $2015 \mathrm{ESC} /$ ERS guidelines [13]. In addition to the general procedures of the EuMiClip Registry, in the Italian arm of the registry we assessed GLS using STE according to procedures of our laboratory [14]. In particular, peak negative longitudinal strain was measured from 6 segments in each of the three apical views (long-axis, 4and 2-chamber), and GLS calculated as the average of individual peak strain before aortic valve closure. GLS values were considered positive $($ sign + ) to strengthen the clinical meaning: the higher the values, the better is the strain deformation. Reproducibility of GLS in our laboratory has been recently reported [15].

MR was firstly assessed by color Doppler derived regurgitant jet area as recommended [16]. More than mild MR was computed using quantitative methods, including vena contracta width and/or proximal isovelocity surface area (PISA) when feasible. MR was classified by etiology as "primary" if due to intrinsic valve disease, "secondary" if no valve structural abnormalities were evident, or "mixed" if both LV remodeling with mitral valve tethering and structural valve lesions were present. Causes of primary MR (e.g. degenerative, rheumatic, Barlow's disease, endocarditis) and/or secondary MR were listed (e.g. ischemic, dilated cardiomyopathy). Information on jet direction (central, medial, lateral, and complex) and presence and degree of calcification and valve segment involved (segment 1,2 or 3 ) were collected in patients with moderate to severe MR. In these patients, mechanisms of MR based on the Carpentier's classification of leaflet motion were also reported: type I, normal leaflet motion; type II, excessive leaflet motion; type III, a-restricted leaflet opening, b-restricted leaflet closure [17]. Concomitant hemodynamically significant valve heart diseases were also searched and reported.

\section{Statistical analysis}

Statistical analyses were performed using SPSS package, release 12.0 (SPSS Inc., Chicago, Illinois, USA). Normal 
distribution of data was checked using the KolmogorovSmirnov test. Differences between variables were assessed using the paired $t$ test or one-factor ANOVA as appropriate. Chi-square analysis was used to calculate inter-group rate difference of given parameters. Univariate correlates of a given variable were evaluated by least squares linear regression with computation of means and 95\% confidence intervals $(\mathrm{CI})$. Multiple linear regression analysis was performed to identify independent correlates of a given variable, after adjusting for confounders. Multicollinearity was assessed by computation of in-model variance inflation factor. Intra- and inter-observer variability of LA volume, LV end-diastolic volume, end-systolic volume and PASP was assessed by calculating intra-class correlation coefficient (ICC) within 95\% confidence intervals (CI). The null hypothesis was rejected at 2 -tailed $p<0.05$.

\section{Results}

\section{Distribution and echocardiographic features}

Among 1820 patients referring to our echo lab for different cardiac pathologies during the 3 months recruitment period, 504 (27.7\%) had evidence of MR of variable degree. Patients' characteristics are summarized in Table 1. The mean age was 59.6 years, with a larger prevalence of women; 21 patients (4\%) showed atrial fibrillation at the time of the echocardiographic exam. 109 patients were obese (body mass index $\geq 30 \mathrm{~kg} / \mathrm{m}^{2}$ ) and 161 hypertensive ( $\mathrm{BP} \geq 140 / 90 \mathrm{mmHg}$ ) (data not shown in table).

Classification and degree of MR, along with the main anatomical features, are reported in Table 2 . The majority of MR patients (85.5\%) had a primary etiology (59 with moderate to severe MR. The prevalence of secondary MR was $10.5 \%(n=53)$, with a rate of moderate to severe MR of $66 \%$, while very few patients $(4 \%, n=20)$ exhibited MR with mixed etiology (18 with moderate to severe MR). Prevalence of concomitant hemodynamically significative (more than mild) heart valve diseases are reported. Tricuspid regurgitation was the most frequent (11\% of the overall population), followed by aortic regurgitation.

Table 1 Study population characteristics

\begin{tabular}{lll}
\hline Variable & Mean \pm SD & Range \\
\hline Sex (M/F) & $275 / 229$ & - \\
Age (years) & $59.6 \pm 14.3$ & $15-93$ \\
Body Weight (Kg) & $72.9 \pm 15.2$ & $26-164$ \\
Height (m) & $1.65 \pm 0.10$ & $1.10-2.38$ \\
BMl (Kg/m $\left.{ }^{2}\right)$ & $26.6 \pm 4.9$ & $12.1-50.6$ \\
Heart Rate (bpm) & $69.5 \pm 12.3$ & $45-146$ \\
Systolic BP (mmHg) & $129.0 \pm 17.0$ & $85-200$ \\
Diastolic BP (mmHg) & $77.1 \pm 9.3$ & $50-110$ \\
Atrial Fibrillation (n/\%) & $21 / 4 \%$ & - \\
\hline
\end{tabular}

$B P$ Blood pressure, BMI Body mass index
Table 2 Classification of MR based on etiology, mechanism, degree and frequencies of concomitant valve disease in the study population

\begin{tabular}{llll}
\hline Variable & & Frequencies & $\begin{array}{l}\text { Percentage } \\
(\%)\end{array}$ \\
\hline Etiology & Primitive & 431 & 85.5 \\
& Secondary & 53 & 10.5 \\
& Mixed & 20 & 4 \\
Degree & Mild & 392 & 77.8 \\
& Moderate & 104 & 20.6 \\
Mechanism ${ }^{\text {a }}$ (Carpentier's & Severe & 8 & 1.6 \\
Classification) & Type I & 14 & 12.5 \\
& Type II & 4 & 2.7 \\
& Type III a & 53 & 46.4 \\
& Type III b & 41 & 34.8 \\
Concomitantsignificative & Mitral Stenosis & 1 & 0.2 \\
valve disease & Aortic & 22 & 4 \\
& Regurgitation & & \\
& Aortic Stenosis & 7 & 1 \\
& Tricuspid & 55 & 11 \\
& regurgitation & & \\
\hline
\end{tabular}

anly for patients with moderate to severe MR

LVEF was $59.9 \pm 7.4 \%$ (range $28-77 \%$ ), LAVi $31.6 \pm$ $12.5 \mathrm{ml} / \mathrm{m}^{2}$ (range 12.8-101.3), estimated PASP $19.8 \pm$ $3.7 \mathrm{mmHg}$ (range $5-28 \mathrm{mmHg}$ ), and GLS $19.8 \pm 3.7 \%$ (5-28\%). The feasibility of GLS was almost optimal, it being quantifiable in 460 of the 504 enrolled patients (91\%).

Figure 1 depicts the differences in LVEF and GLS according to MR degree. Both LVEF and GLS were lower in moderate than in mild MR, whereas there was no significant difference between moderate and severe MR. Greater LV size and LA volume, lower LVEF and GLS, and higher PAPS (all $p<0.0001$ ) were also observed in moderate to severe MR compared to mild MR (Table 3).

\section{Univariate correlations and independent associations}

LVEF and GLS were positively related one another in the pooled population $(r=0.71)$, and in both subanalysis in patients with mild $(r=0.51)$ and moderate to severe MR ( $\mathrm{r}=0.84) \quad($ all $\mathrm{p}<0.0001)$ (Fig. 2). However, when considering the $95 \% \mathrm{CI}$ of the normal relation, particularly in the subgroup with mild MR, a certain number of MR patients were above the upper or below the lower limits. Differently, only 2 patients were below the $95 \% \mathrm{CI}$ of the normal relation in the subgroup with moderate to severe MR.

Figure 3 depicts univariate correlations of both LVEF and GLS in the pooled MR population (top) and in patients with moderate to severe MR (bottom). Of note, both LVEF and GLS correlated negatively with PASP in the entire 


\section{LV function according different degree of MR}
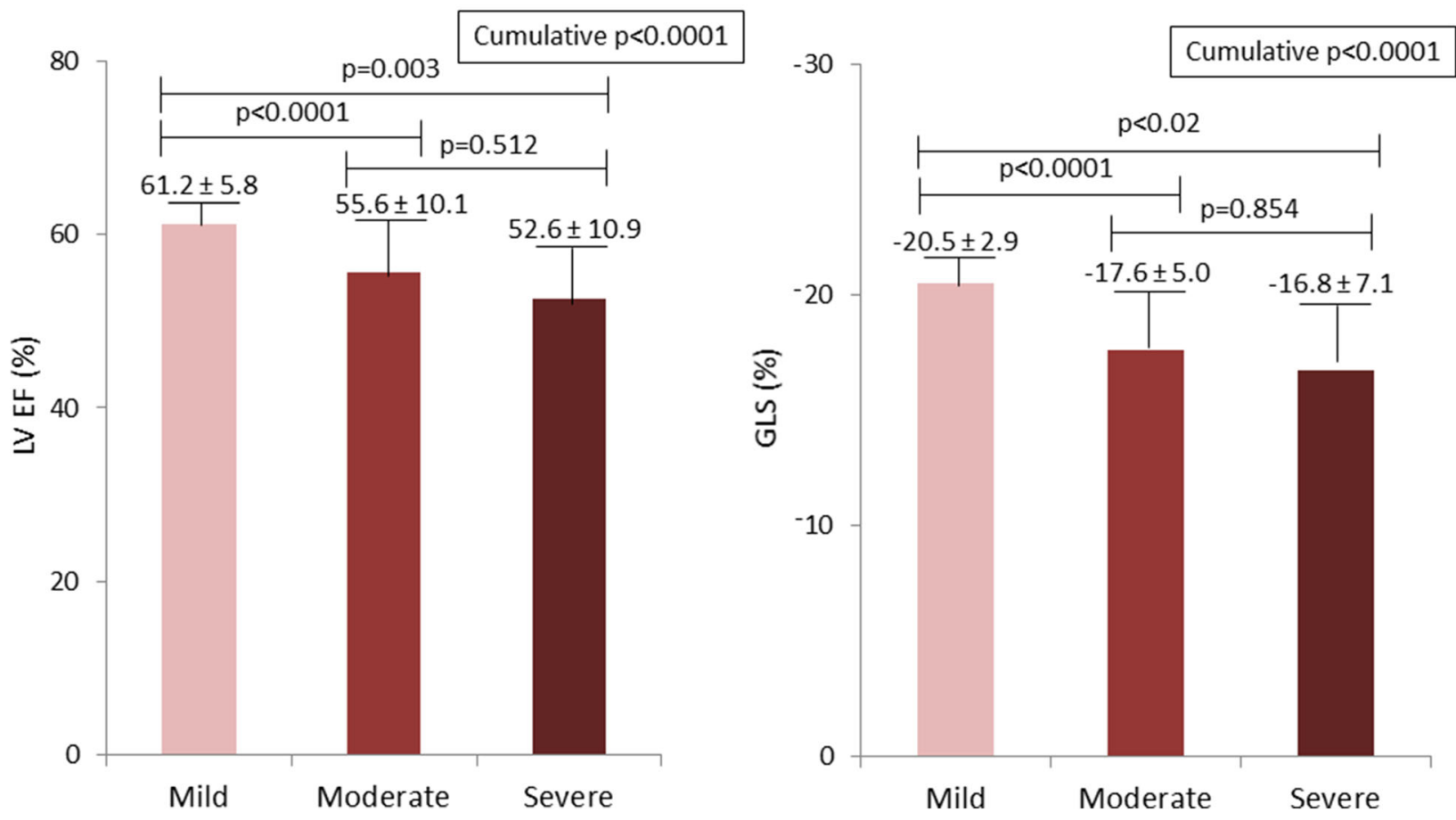

Fig. 1 Differences in left ventricular ejection fraction (LVEF) and global longitudinal strain (GLS) by MR degree

study population but, in presence of moderate to severe MR only the correlation with GLS remained significant.

Table 4 shows independent associations of LVEF and GLS, after adjusting for age, body mass index, heart rate and systolic BP obtained by multiple regression analyses in the pooled population and, separately, in patients with mild and moderate to severe MR. In the pooled population, both parameters were independently and negatively associated with LV diameters and volumes as well as with LA size and PASP. In the subgroup with mild MR, only GLS maintained an independent association with PASP. In patients with moderate to severe MR, GLS had a more significant association with LAVi than LVEF $(p<0.005$ and $p=0.008$, respectively) and showed a significant association with PASP $(p=0.004)$, which was not evident for LVEF $(p=0.09)$.

Reproducibility analyses of standard echocardiographic parameters were performed in 20 of our study patients (Additional file 1: Table S1): notably, both intra- and inter-observer reproducibility of GLS was substantially higher than that of LVEF.

\section{Discussion}

In the present study, during a 3-month assessment period of the European Registry of MR in our general

Table 3 Differences of echocardiographic parameters between patients with mild vs. moderate to severe MR

\begin{tabular}{llll}
\hline Variable & $\begin{array}{l}\text { Mild MR } \\
n=392\end{array}$ & $\begin{array}{l}\text { Moderate to severe MR } \\
n=112\end{array}$ & $p$ \\
\hline LV end-diastolic diameter $(\mathrm{mm})$ & $49.3 \pm 6.0$ & $53.4 \pm 7.8$ & $<0.0001$ \\
LV end-systolic diameter $(\mathrm{mm})$ & $31.6 \pm 6.0$ & $36.2 \pm 9.6$ & $<0.0001$ \\
LV end-diastolic volume $(\mathrm{ml})$ & $86.9 \pm 27.9$ & $104.2 \pm 38.6$ & $<0.0001$ \\
LV end-systolic volume $(\mathrm{ml})$ & $33.9 \pm 13.5$ & $49.9 \pm 28.3$ & $<0.0001$ \\
LV EF (\%) & $61.2 \pm 5.8$ & $55.4 \pm 10.1$ & $<0.0001$ \\
GLS (\%) & $20.5 \pm 3.0$ & $17.5 \pm 5.2$ & $<0.0001$ \\
LAVi $\left(\mathrm{ml} / \mathrm{m}^{2}\right)$ & $28.5 \pm 8.5$ & $42.6 \pm 17.3$ & $<0.0001$ \\
Estimated PASP (mmHg) & $29.6 \pm 7.5$ & $36.9 \pm 11.1$ & $<0.0001$ \\
\hline
\end{tabular}




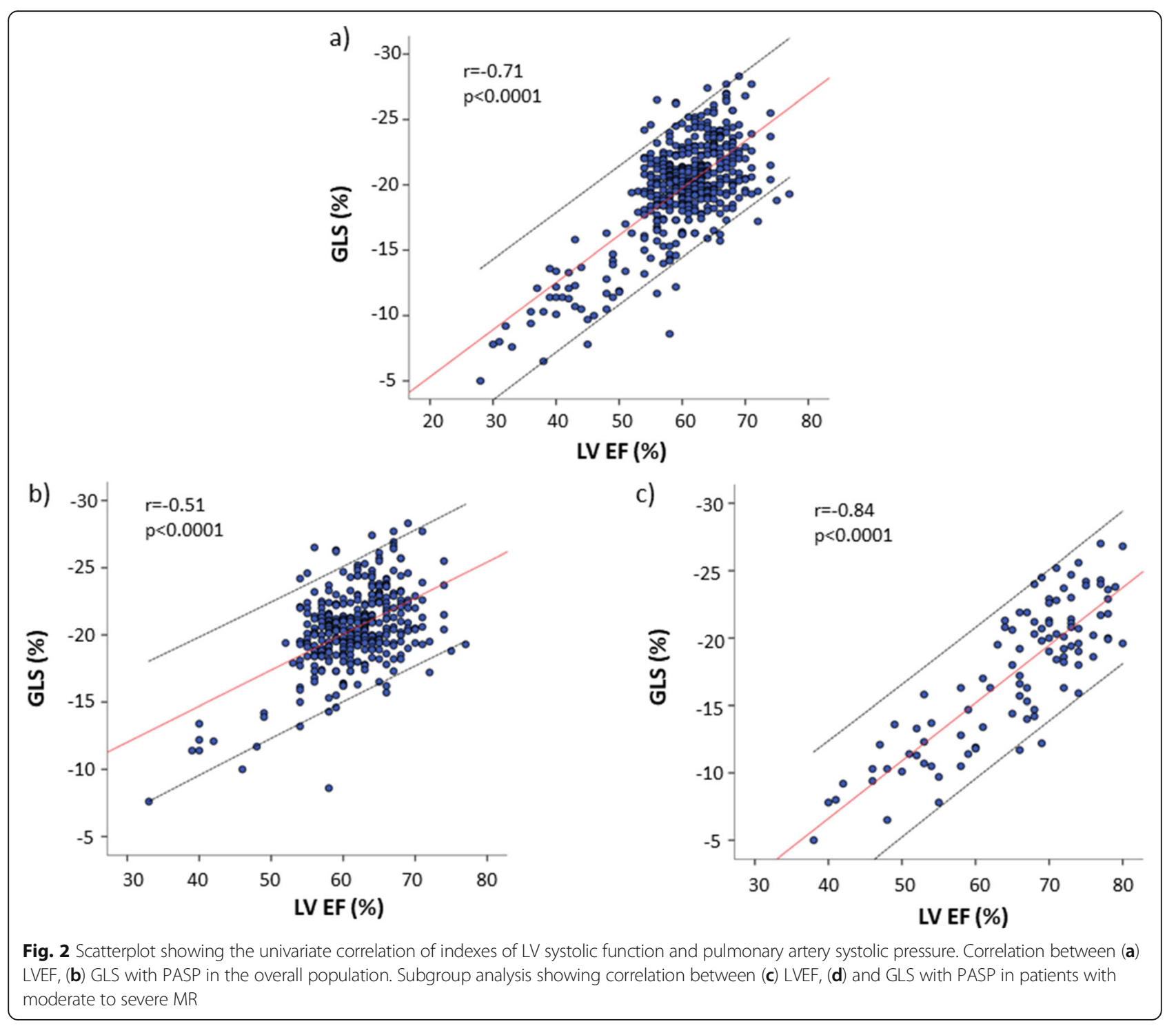

hospital echocardiographic laboratory, $27.7 \%$ of patients were diagnosed MR of variable degree. GLS measurement was able to provide valuable clinical information for the detection of target organ damage in this clinical setting. Notably, GLS was obtained in $91 \%$ of MR patients, thus demonstrating an almost optimal feasibility. The head-to-head comparison between LVEF and GLS showed that (i) LVEF and GLS are both lower in moderate and severe than in mild MR, (ii) the relation between LVEF and GLS appears to be flatter in mild than in moderate to severe MR, and (iii) GLS, but not LVEF, is independently associated with increased PASP in mild and in moderate to severe MR.

LVEF is a reference parameter for LV systolic function in the clinical practice and is widely used also in patients with MR to guide decision-making, including the choice for surgery [16], and to predict postoperative LV dysfunction [18-20]. However, due to its strong preload dependence, LVEF is poorly sensitive in detecting early abnormalities of LV contractility [21]. In contrast, despite also being preload-dependent [22], GLS was shown to have significantly better ability to detect early impairment of LV systolic function in both primary [23] and secondary MR [24] and to predict functional capacity in asymptomatic patients with MR and preserved LVEF [25]. GLS is also predictive of post-operative LV dysfunction in MR patients undergoing mitral valve surgery $[26,27]$ or mitral valve repair $[28,29]$. Moreover, LV longitudinal function is the main determinant of mortality in patients with primary MR, whereas resting/exercise LVEF and MR degree at rest have no prognostic value [30].

In the present study, as expected, LVEF and GLS were both lower in moderate to severe MR compared with mild MR, showing a highly significant positive 


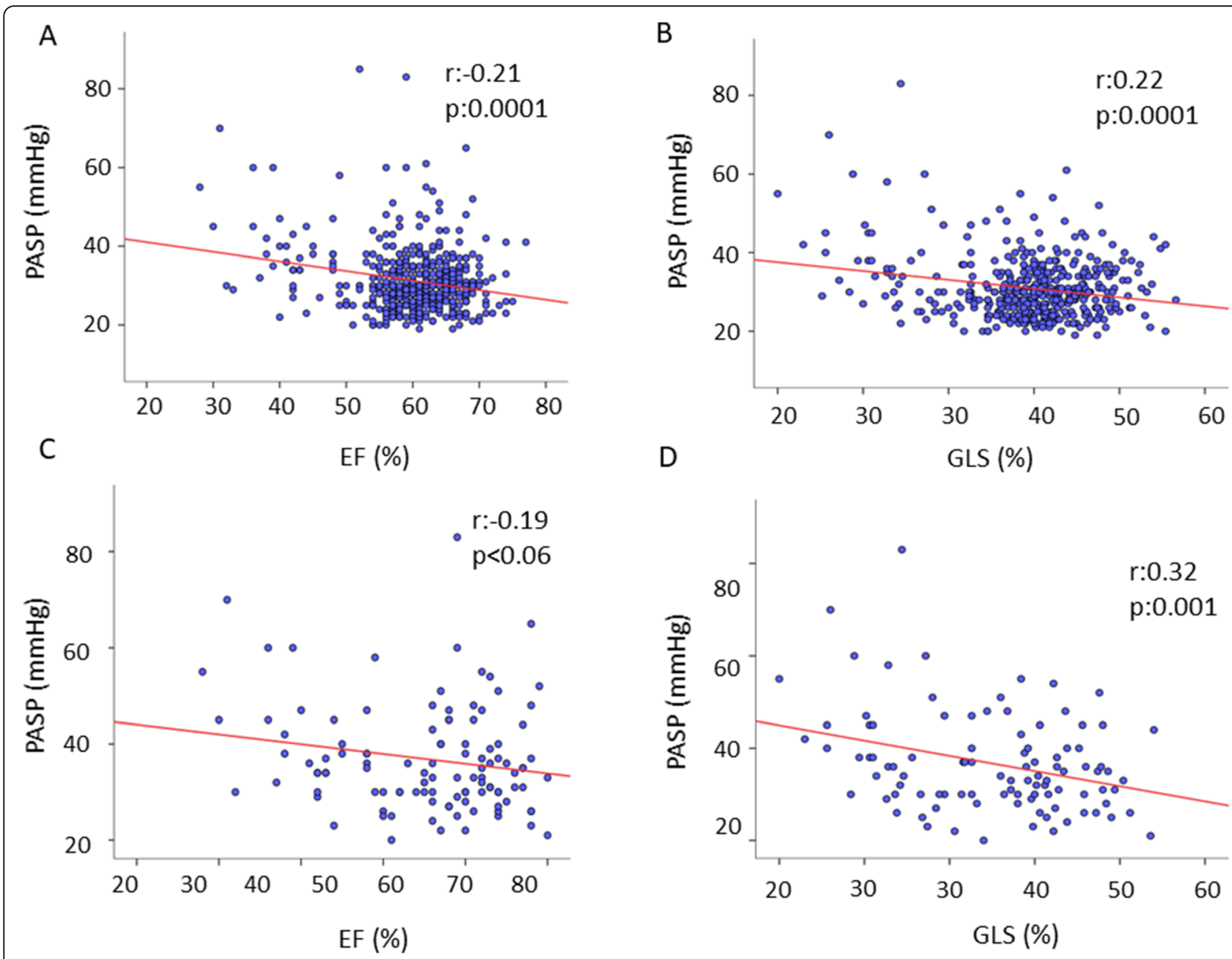

Fig. 3 Relation between left ventricular ejection fraction (LVEF) and global longitudinal strain (GLS) in the pooled population (a), and in patients with mild (b) and moderate to severe mitral regurgitation (MR) (c). Positive relations are seen in all the three groups, but data points for a certain number of MR patients are above the upper and below the lower limit of the 95\% confidence interval (Cl) of the normal relation in (a) and (b) (parallel dotted lines). Conversely, the positive relation in moderate to severe MR (c) exhibits only 2 patients below the $95 \% \mathrm{Cl}$

relationship in the pooled population. Indeed, since LVEF and GLS represent a relative change in volume and length respectively, from a pure mathematical viewpoint it is largely expectable that these two parameters do not correlate in linear fashion [31]. Consistently, in our mild MR subgroup, which mainly includes primary etiology MR and therefore also a lower degree of LV dysfunction, the linear relation between LVEF and GLS was flatter, with few patients with overly higher GLS and a substantially greater number of individuals with disproportionately reduced GLS, in comparison with LVEF. Accordingly, in this subpopulation the proportion of patients with low GLS was greater than that of patients with reduced LVEF. Although we cannot know if GLS reduction in this our subpopulation occurs because MR itself or the concomitance of other cardiovascular risk factors, this finding strongly, albeit indirectly, supports the ability of GLS to detect early, subclinical abnormalities of LV systolic function in mild MR, not identifiable by LVEF itself.

The incremental diagnostic value of GLS was lost in patients with moderate to severe MR, in whom the slope of the regression line of the relation between these two parameters was as much stronger and no significant differences was found in the proportion of patients with reduced GLS and reduced LVEF. It is conceivable that, with the increase of MR severity, the greater burden of loading changes could tend to equalize the relation between GLS and LVEF which becomes more linear.

Additional insights were provided by the univariate and multivariate associations of both LVEF and GLS with the other echocardiographic measurements used in the EuMiClip Registry. In separate multiple linear 
Table 4 Multivariate associations of LV EF and GLS

\begin{tabular}{|c|c|c|c|}
\hline Dependent Variable & Covariate & $\beta$ coefficient & $p$ value \\
\hline \multicolumn{4}{|c|}{ a. in the pooled patients MR } \\
\hline \multirow[t]{7}{*}{ LV EF } & LV end-diastolic diameter & -0.41 & $<0.0001$ \\
\hline & LV end-systolic diameter & -0.54 & $<0.0001$ \\
\hline & LV end-diastolic volume & -0.40 & $<0.0001$ \\
\hline & LV end-systolic volume & -0.71 & $<0.0001$ \\
\hline & LA diameter & -0.25 & $<0.0001$ \\
\hline & LAVi & -0.38 & $<0.0001$ \\
\hline & PASP & -0.18 & $<0.0001$ \\
\hline \multirow[t]{7}{*}{$\mathrm{GLS}^{\mathrm{a}}$} & LV end-diastolic diameter & -0.40 & $<0.0001$ \\
\hline & LV end-systolic diameter & -0.54 & $<0.0001$ \\
\hline & LV end-diastolic volume & -0.40 & $<0.0001$ \\
\hline & LV end-systolic volume & -0.60 & $<0.0001$ \\
\hline & LA diameter & -0.32 & $<0.0001$ \\
\hline & LAVi & -0.41 & $<0.0001$ \\
\hline & PASP & -0.19 & $<0.0001$ \\
\hline \multicolumn{4}{|c|}{ b. In patients with mild MR } \\
\hline \multirow[t]{7}{*}{ LV EF } & LV end-diastolic diameter & -0.24 & $<0.0001$ \\
\hline & LV end-systolic diameter & -0.37 & $<0.0001$ \\
\hline & LV end-diastolic volume & -0.22 & $<0.0001$ \\
\hline & LV end-systolic volume & -0.62 & $<0.0001$ \\
\hline & LA diameter & -0.05 & 0.417 \\
\hline & LAVi & -0.22 & $<0.0001$ \\
\hline & PASP & -0.02 & 0.735 \\
\hline \multirow[t]{7}{*}{$\mathrm{GLS}^{\mathrm{a}}$} & LV end-diastolic diameter & -0.20 & $<0.0001$ \\
\hline & LV end-systolic diameter & -0.35 & $<0.0001$ \\
\hline & LV end-diastolic volume & -0.25 & $<0.0001$ \\
\hline & LV end-systolic volume & -0.45 & $<0.0001$ \\
\hline & LA diameter & -0.13 & 0.04 \\
\hline & LAVi & -0.23 & $<0.0001$ \\
\hline & PASP & -0.18 & $=0.003$ \\
\hline \multicolumn{4}{|c|}{ c. In patients with moderate to severe MR } \\
\hline \multirow[t]{7}{*}{ LV EF } & LV end-diastolic diameter & -0.50 & $<0.0001$ \\
\hline & LV end-systolic diameter & -0.59 & $<0.0001$ \\
\hline & LV end-diastolic volume & -0.46 & $<0.0001$ \\
\hline & LV end-systolic volume & -0.72 & $<0.0001$ \\
\hline & LA diameter & -0.21 & 0.03 \\
\hline & LAVi & -0.27 & 0.008 \\
\hline & PASP & -0.17 & 0.09 \\
\hline \multirow[t]{7}{*}{ GLS ${ }^{a}$} & LV end-diastolic diameter & -0.47 & $<0.0001$ \\
\hline & LV end-systolic diameter & -0.59 & $<0.0001$ \\
\hline & LV end-diastolic volume & -0.41 & $<0.0001$ \\
\hline & LV end-systolic volume & -0.61 & $<0.0001$ \\
\hline & LA diameter & -0.25 & $<0.02$ \\
\hline & LAVi & -0.29 & $<0.005$ \\
\hline & PASP & -0.30 & $=0.004$ \\
\hline
\end{tabular}

Abbreviations as in Table 4

"Values of GLS considered as "positive" (sign +) to build the associations in order to strengthen their clinical meaning: the higher values the better strain deformation independent on the plus/minus sign regression analyses, body mass index as an expression of LV preload, systolic BP accounting for afterload, heart rate and age were chosen as potential confounders. By adjusting for these variables, both LVEF and GLS were independently and strongly associated with indices of preload (LV end-diastolic diameter and volume, LAVi) and afterload (LV end-systolic diameter and volume) in the pooled population and, separately, in mild and moderate to severe MR, well reflecting cardiac pathophysiology of MR. The association of both LVEF and GLS with PASP was strongly significant in the pooled model, whereas interesting discrepancies were observed when groups were analyzed separately: the association of GLS with PASP remained statistically significant, whereas that of LVEF with PASP disappeared in both the subgroups with mild and moderate to severe MR. During MR progression, passive backward transmission of elevated LA pressure leads to post-capillary pulmonary artery pressure elevation. In the 2016 ASE/EACVI recommendations for the evaluation of LV diastolic function [32], non-invasive estimation of PASP by tricuspid regurgitation velocity is considered one of the key parameters for identifying patients with increased LV filling pressures (LVFP). Additionally, PASP estimation provides incremental prognostic usefulness to standard clinical predictors in patients with primary MR [33], including those undergoing surgery for degenerative mitral valve disease [34, 35]. Noteworthy, LVFP increase and subsequent PASP elevation in MR are mediated by LA enlargement, which is a function of elevated preload and LA pressure as well, and of myocardial fibrosis occurring in the late disease stages $[36,37]$. Accordingly, LA size of our patients was greater in moderate to severe than in mild MR, and the magnitude of the independent association with LAVi was slightly greater for GLS than for LVEF.

\section{Limitations}

As a subanalysis of the EuMiClip Registry [10], patients with a broad spectrum of indications for echocardiographic exam were included, thus different comorbidity could act as confounding factors altering the pathological path of MR disease. Comparison analysis on GLS data with the other arms of the EuMiclip registry was not achievable due to intervendor variability. This limited the study analysis to the sole population included in our laboratory and hindered separate subanalysis according to mechanism and etiology of MR, due to low statistical power. Indeed, 'primary' and 'secondary' MR are distinctly different diseases in their etiologies, pathophysiology and in therapies and it is not easy to make common considerations between these two clinical conditions. 


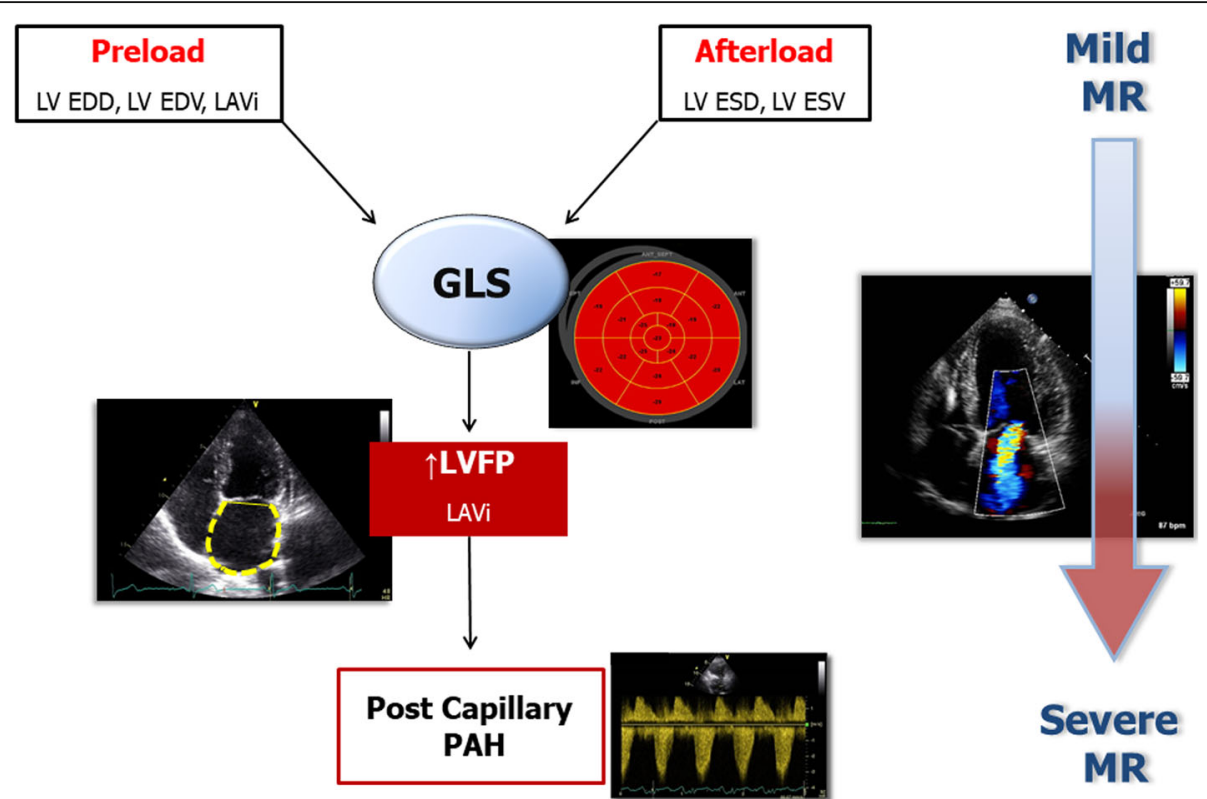

Fig. 4 Schema depicting the central role of global longitudinal strain (GLS) in detecting cardiac damage in mitral regurgitation (MR). LAVi= left atrial volume index; LVEDD = left ventricular end-diastolic diameter; LVEDV = left ventricular end-diastolic volume; LVESD = left ventricular endsystolic diameter; LVESV = left ventricular end-systolic volume; LVFP = left ventricular filling pressure; PAH = pulmonary arterial hypertension

Furthermore, the small sample size of patients with severe MR is consistent with the characteristics of patients referred to our general hospital echocardiographic laboratory, where only few pre-surgical MR patients are examined. Laboratories connected with cardiac surgery departments can easily collect data from larger numbers of patients with severe MR that are candidate to invasive diagnostic and interventional procedures.

Finally, although the last chamber quantification recommendations propose possible reference normal values of GLS [12], the definition of "normal" GLS in subjects without cardiovascular disease remains to be elucidated. Some studies have described the higherthan-normal values of GLS in chronic severe MR, as the pathophysiological condition (reduced afterload and increased preload) results in a state of hypernormal LV function [38]. These findings also suggests that GLS is a load-dependent and should be therefore corrected for LV volumes. Accordingly, in the present study we could not indicate a clear cut-off point of GLS to be considered as definitively normal in the setting of MR.

\section{Conclusions}

In the Italian arm of the EuMiClip Registry, LVEF and GLS are related one another but their relation appears to be flatter in the group with mild MR. In this subgroup, GLS shows a greater ability in detecting impairment of LV systolic function. LVEF and GLS are both independently associated with the main echo parameters of LV and LA size, but only GLS is related to PASP in mild and moderate to severe MR. The recognized optimal feasibility and reproducibility of GLS, substantially greater than that of LVEF $[39,40]$, is also confirmed in the present study. Our findings highlight therefore the central role of GLS as a hallmark of cardiac damage in patients with MR (Fig. 4). GLS is more sensitive than LVEF in detecting early impairment of LV systolic function in mild MR. Differently from LVEF, GLS is also a clue of elevated LA pressure and post-capillary pulmonary hypertension as an expression of increased LV filling pressures, both in mild and moderate to severe MR. GLS can be useful across all the spectrum of MR patients for guiding management, stratifying prognosis, and possibly establishing the appropriate timing for interventional procedures.

\section{Supplementary information}

Supplementary information accompanies this paper at https://doi.org/10. 1186/s12947-019-0178-7.

Additional file 1: Table S1. Reproducibility of standard echocardiographic parameters

\section{Abbreviations}

ASE: American Society of Echocardiography; Cl: Confidence interval; EACVl: European Association of Cardiovascular Imaging; GLS: Global longitudinal strain; ICC: Intraclass correlation coefficient; LA: Left atrial; LAVi: Left atrial volume index; LV: Left ventricular; LVEF: Left ventricular ejection fraction; MR: Mitral regurgitation; PASP: Pulmonary arterial systolic pressure; PISA: Proximal isovelocity surface area; STE: Speckle Tracking Echocardiography 


\section{Acknowledgments}

Dr. Santoro and Dr. Sorrentino are supported by a research grant from the International PhD program in Cardiovascular Pathophysiology and Therapeutics CardioPath.

\section{Authors' contributions}

$C S, M G$ and JLZ designed the study and drafted the manuscript, RE, AB and JMM participated in the design of the study and performed the statistical analyses, RS and ML participated in the study design and coordination and helped to draft the manuscript, CFG and BT conceived the study and its designed and revised critically the final manuscript. All authors read and approved the final manuscript.

\section{Funding}

No funding.

\section{Availability of data and materials}

Availability of data and material under request.

\section{Ethics approval and consent to participate}

Ethics approval from Federico II University Hospital Naples. Informed consent obtained from each patient.

\section{Consent for publication}

Consent for publication obtained by all the authors.

\section{Competing interests}

The authors declare that they have no competing interests.

\section{Author details}

'Department of Advanced Biomedical Science, Interdepartmental Laboratory of Cardiac Imaging, Federico II University Hospital, V. S. Pansini 5, bld 1, 80131 Naples, Italy. ${ }^{2}$ Department of Cardiology, University Hospital Ramon y Cajal, Madrid, Spain.

Received: 16 July 2019 Accepted: 8 November 2019

Published online: 21 November 2019

\section{References}

1. lung B, Baron G, Butchart EG, Delahaye F, Gohlke-Bärwolf C, Levang OW, Tornos P, Vanoverschelde JL, Vermeer F, Boersma E, Ravaud P, Vahanian A A prospective survey of patients with valvular heart disease in Europe: the euro heart survey on Valvular heart disease. Eur Heart J. 2003;24:1231-43.

2. Nishimura RA, Otto CM, Bonow RO, Carabello BA, Erwin JP 3rd, Guyton RA, O'Gara PT, Ruiz CE, Skubas NJ, Sorajja P, Sundt TM 3rd, Thomas JD; American College of Cardiology/American Heart Association Task Force on Practice Guidelines. 2014 AHA/ACC guideline for the management of patients with valvular heart disease: a report of the American College of Cardiology/American Heart Association Task Force on Practice Guidelines. J Am Coll Cardiol 2014;63:2438-2488.

3. Baumgartner H, Falk V, Bax JJ, De Bonis M, Hamm C, Holm PJ, lung B, Lancellotti P, Lansac E, Rodriguez Muñoz D, Rosenhek R, Sjögren J, Tornos Mas P, Vahanian A, Walther T, Wendler O, Windecker S, Zamorano JL, ESC Scientific Document Group. 2017 ESC/EACTS guidelines for the management of valvular heart disease. Eur Heart J. 2017;38:2739-91.

4. Dudzinski DM, Hung J. Echocardiographic assessment of ischemic mitral regurgitation. Cardiovasc Ultrasound. 2014;12:46.

5. Eckberg DL, Gault JH, Bouchard RL, Karliner JS, Ross J Jr. Mechanics of left ventricular contraction in chronic severe mitral regurgitation. Circulation. 1973:47:1252-9.

6. Dalla K, Hallman C, Bech-Hanssen O, Haney M, Ricksten SE. Strain echocardiography identifies impaired longitudinal systolic function in patients with septic shock and preserved ejection fraction. Cardiovasc Ultrasound. 2015;13:30.

7. Romano S, Mansour IN, Kansal M, Gheith H, Dowdy Z, Dickens CA, ButoColletti C, Chae JM, Saleh HH, Stamos TD. Left ventricular global longitudinal strain predicts heart failure readmission in acute decompensated heart failure. Cardiovasc Ultrasound. 2017;15:6.

8. Kim MS, Kim YJ, Kim HK, Han JY, Chun HG, Kim HC, Sohn DW, Oh BH, Park YB. Evaluation of left ventricular short- and long-axis function in severe mitral regurgitation using 2-dimensional strain echocardiography. Am Heart J. 2009;157:345-51.

9. Park JJ, Park JB, Park JH, Cho GY. Global longitudinal strain to predict mortality in patients with acute heart failure. J Am Coll Cardiol. 2018;71: 1947-57.

10. Monteagudo Ruiz JM, Galderisi M, Buonauro A, Badano L, Aruta P, Swaans MJ, Sanchis L, Saraste A, Monaghan M, Theodoropoulos KC, Papitsas M, LielCohen N, Kobal S, Bervar M, Berlot B, Filippatos G, Ikonomidis I, Katsanos S, Tanner FC, Cassani D, Faletra FF, Leo LA, Martinez A, Matabuena J, GrandeTrillo A, Alonso-Rodriguez D, Mesa D, Gonzalez-Alujas T, Sitges M, CarrascoChinchilla F, Li CH, Fernandez-Golfin C, Zamorano JL. Overview of mitral regurgitation in Europe: results from the European Registry of mitral regurgitation (EuMiClip). Eur Heart J Cardiovasc Imaging. 2018;19:503-7.

11. Galderisi M, Cosyns B, Edvardsen T, Cardim N, Delgado V, Di Salvo G, Donal E, Sade LE, Ernande L, Garbi M, Grapsa J, Hagendorff A, Kamp O, Magne J, Santoro C, Stefanidis A, Lancellotti P, Popescu B, Habib G; 2016-2018 EACVI scientific documents committee; 2016-2018 EACVI scientific documents committee. 2016-2018 EACVI scientific documents committee. Standardization of adult transthoracic echocardiography reporting in agreement with recent chamber quantification, diastolic function, and heart valve disease recommendations: an expert consensus document of the European Association of Cardiovascular Imaging. Eur Heart J Cardiovasc Imaging 2017;18:1301-1310.

12. Lang RM, Badano LP, Mor-Avi V, Afilalo J, Armstrong A, Ernande L, Flachskampf FA, Foster E, Goldstein SA, Kuznetsova T, Lancellotti P, Muraru D, Picard MH, Rietzschel ER, Rudski L, Spencer KT, Tsang W, Voigt JU. Recommendations for cardiac chamber quantification by echocardiography in adults: an update from the American Society of Echocardiography and the European Association of Cardiovascular Imaging. Eur Heart J Cardiovasc Imaging. 2015;15:233-70.

13. Galiè N, Humbert M, Vachiery JL, Gibbs S, Lang I, Torbicki A, Simonneau G, Peacock A, Vonk Noordegraaf A, Beghetti M, Ghofrani A, Gomez Sanchez MA, Hansmann G, Klepetko W, Lancellotti P, Matucci M, McDonagh T, Pierard LA, Trindade PT, Zompatori M, Hoeper M; ESC Scientific Document Group. 2015 ESC/ERS guidelines for the diagnosis and treatment of pulmonary hypertension: the joint task force for the diagnosis and treatment of pulmonary hypertension of the European Society of Cardiology (ESC) and the European Respiratory Society (ERS): endorsed by: Association for European Paediatric and Congenital Cardiology (AEPC), International Society for Heart and Lung Transplantation (ISHLT). Eur Heart J 2016 1;37:67-119.

14. Lembo M, Esposito R, Lo ludice F, Santoro C, Izzo R, De Luca N, Trimarco B, de Simone G, Galderisi M. Impact of pulse pressure on left ventricular global longitudinal strain in normotensive and newly diagnosed, untreated hypertensive patients. J Hypertens. 2016;34:1201-7.

15. Alcidi GM, Esposito R, Evola V, Santoro C, Lembo M, Sorrentino R, Lo ludice F, Borgia F, Novo G, Trimarco B, Lancellotti P, Galderisi M. Normal reference values of multilayer longitudinal strain according to age decades in a healthy population: a single-Centre experience. Eur Heart J Cardiovasc Imaging. 2017;19:1390-6.

16. Lancellotti P, Tribouilloy C, Hagendorff A, Popescu BA, Edvardsen T, Pierard LA, Badano L, Zamorano JL, scientific document Committee of the European Association of cardiovascular imaging. Scientific document Committee of the European Association of cardiovascular imaging. Recommendations for the echocardiographic assessment of native valvular regurgitation: an executive summary from the European association of cardiovascular imaging. Eur Heart J Cardiovasc Imaging. 2013;14:611-44.

17. Carpentier A, Chauvaud S, Fabiani JN, Deloche A, Relland J, Lessana A, D'Allaines C, Blondeau P, Piwnica A, Dubost C. Reconstructive surgery of mitral valve incompetence: ten-year appraisal. J Thorac Cardiovasc Surg. 1980;79:338-48.

18. Matsumura T, Ohtaki E, Tanaka K, Misu K, Tobaru T, Asano R, Nagayama M, Kitahara K, Umemura J, Sumiyoshi T, Kasegawa H, Hosoda S. Echocardiographic prediction of left ventricular dysfunction after mitral valve repair for mitral regurgitation as an indicator to decide the optimal timing of repair. J Am Coll Cardiol. 2003;42:458-63.

19. Enriquez-Sarano M, Tajik AJ, Schaff HV, Orszulak TA, Bailey KR, Frye RL. Echocardiographic prediction of survival after surgical correction of organic mitral regurgitation. Circulation. 1994;90:830-7.

20. Enriquez-Sarano M, Tajik AJ, Schaff HV, Orszulak TA, McGoon MD, Bailey KR, Frye RL. Echocardiographic prediction of left ventricular function after 
correction of mitral regurgitation: results and clinical implications. J Am Coll Cardiol. 1994;24:1536-43.

21. Raymond L, Marwick TH. Assessment of subclinical left ventricular dysfunction in asymptomatic mitral regurgitation. Eur J Echocardiogr. 2007; 8:175-84.

22. Choi JO, Shin DH, Cho SW, Song YB, Kim JH, Kim YG, Lee SC, Park SW. Effect of preload on left ventricular longitudinal strain by $2 \mathrm{D}$ speckle tracking. Echocardiography. 2008;25:873-9.

23. Lancellotti P, Cosyns B, Zacharakis D, Attena E, Van Camp G, Gach O, Rademaker M, Pierard LA. Importance of left ventricular longitudinal function and functional reserve in patients with degenerative mitral regurgitation: assessment by two-dimensional speckle tracking. J Am Soc Echocardiogr. 2008;21:1331-6.

24. Kamperidis V, Marsan NA, Delgado V, Bax JJ. Left ventricular systolic function assessment in secondary mitral regurgitation: left ventricular ejection fraction vs. speckle tracking global longitudinal strain. Eur Heart J. 2016;37:811-6.

25. Mentias A, Naji P, Gillinov AM, Rodriguez LL, Reed G, Mihaljevic T, Suri RM, Sabik JF, Svensson LG, Grimm RA, Griffin BP, Desai MY. Strain echocardiography and functional capacity in asymptomatic primary mitral regurgitation with preserved ejection fraction. J Am Coll Cardiol. 2016;68: 1974-86.

26. Mascle $\mathrm{S}$, Schnell E, Thebault $\mathrm{C}$, Corbineau H, Laurent M, Harmonic $\mathrm{S}$, Veillard D, Mabo P, Lequemer A, Donal E. Predictive value of global longitudinal strain in a surgical population of organic mitral regurgitation. J Am Soc Echocardiogr. 2012;25:766-72.

27. de Isla LP, de Agustin A, Rodrigo JL, Almeria C, del Cramen MM, Rodriquez E, Garcia A, Macaya C, Zamorano JL. Chronic mitral regurgitation: a pilot study to assess preoperative left ventricular contractile function using speckle-tracking echocardiography. J Am Soc Echocardiogr. 2009;22:831-8.

28. Witkowski TG, Thomas JD, Debonnaire PJ, Delgado V, Hoke U, Ewe SH Versteegh MI, Holman ER, Schalli MJ, Bax JJ, Klautz RJ, Marsan NA. Global longitudinal strain predicts left ventricular dysfunction after mitral valve repair. Eur J Echocardiogr. 2013;14:69-76.

29. Pandis D, Sengupta PP, Castillo JG, Caracciolo G, Fischer GW, Narula J, Anyanwu A, Adams DH. Assessment of longitudinal myocardial mechanics in patients with degenerative mitral valve regurgitation predicts postoperative worsening of left ventricular systolic function. J Am Soc Echocardiogr. 2014;27:627-38

30. Magne J, Mahjoub H, Pibarot P, Pirlet C, Pierard LA, Lancellotti P. Prognostic importance of exercise brain natriuretic peptide in asymptomatic degenerative mitral regurgitation. Eur J Heart Fail. 2012;14:1293-302.

31. Lipiec P, Wiśniewski J, Kasprzak JD. Should we search for linear correlations between global longitudinal strain parameters and ejection fraction? Eur Heart J Cardiovasc Imaging. 2014;15(11):1301.

32. Nagueh SF, Smiseth OA, Appleton CP, Byrd BF 3rd, Dokainish H, Edvardsen T, Flachskampf FA, Gillebert TC, Klein AL, Lancellotti P, Marino P, Oh JK, Alexandru Popescu B, Waggoner AD. Recommendations for the evaluation of left ventricular diastolic function by echocardiography: an update from the American Society of Echocardiography and the European Association of Cardiovascular Imaging. Eur Heart J Cardiovasc Imaging. 2016;17:1321-60.

33. Svensson LG, Griffin BP, Desai MY. Effect of pulmonary vascular pressures on long-term outcome in patients with primary mitral regurgitation. J Am Coll Cardiol. 2016;67:2952-61.

34. Ghoreishi M, Evans CF, De Filippi CR, Hobbs G, Young CA, Gammie JS. Pulmonary hypertension adversely affects short- and long-term survival after mitral valve operation for mitral regurgitation: implications for timing of surgery. J Thorac Cardiovasc Surg. 2011;142:1439-52.

35. Nozohoor S, Hyllen S, Meurling C, Wierup P, Sjogren J. Prognostic value of pulmonary hypertension in patients undergoing surgery for degenerative mitral valve disease with leaflet prolapse. J Card Surg. 2012;27:668-75.

36. Arias A, Pizarro R, Oberti P, Falconi M, Lucas L, Sosa F, Funes D, Cagide A. Prognostic value of left atrial volume in asymptomatic organic mitral regurgitation. J Am Soc Echocardiogr. 2013;26:699-705.

37. Ciampi Q, Villari B. Role of echocardiography in diagnosis and risk stratification in heart failure with left ventricular systolic dysfunction. Cardiovasc Ultrasound. 2007;5:34.

38. Rösner A, Bijnens B, Hansen M, How OJ, Aarsaether E, Müller S, Sutherland GR, Myrmel T. Left ventricular size determines tissue Doppler-derived longitudinal strain and strain rate. Eur J Echocardiogr. 2009;10:271-7.

39. Thavendiranathan P, Grant AD, Negishi T, Plana JC, Popović ZB, Marwick TH. Reproducibility of echocardiographic techniques for sequential assessment of left ventricular ejection fraction and volumes: application to patients undergoing cancer chemotherapy. J Am Coll Cardiol. 2013;61:77-84.

40. Farsalinos KE, Daraban AM, Uniu S, Thomas JD, Badano LP, Voigt JU. Headto-head comparison of global longitudinal strain measurements among nine different vendors: the EACVI/ASE inter-vendor comparison study. J Am Soc Echocardiogr. 2015;28:1171-81.

\section{Publisher's Note}

Springer Nature remains neutral with regard to jurisdictional claims in published maps and institutional affiliations.
Ready to submit your research? Choose BMC and benefit from:

- fast, convenient online submission

- thorough peer review by experienced researchers in your field

- rapid publication on acceptance

- support for research data, including large and complex data types

- gold Open Access which fosters wider collaboration and increased citations

- maximum visibility for your research: over $100 \mathrm{M}$ website views per year

At $\mathrm{BMC}$, research is always in progress.

Learn more biomedcentral.com/submissions 